\title{
Development of the Determinants of tactical performance with significance of the monthly Biorhythm and their effect on the results of Kumite Matches in Karate
}

\section{Dr. Ibrahim Ali Abd Elhamid El Ebiary}

\section{Introduction and problem of the research:}

As a theory and applications, sports training rapidly progresses, particularly after many countries dedicated their efforts and human and material capacities to upgrade of sports achievement of their players, because these countries consider the results of international championships and Olympic tournaments as a source of cultural progress of the state and mark of the high economic and scientific level of individuals in society.

Biorhythm is a modern science used in the field of physical education. The performance efficiency of individuals vary from time to time during the same day, same week or month. Biorhythm is very important in the field of sports, particularly after the rise of sports performance and break of records in the international championships and Olympic tournaments. In addition, it is a new approach as an entry to improve the effectiveness of sports training methods and creation of new approaches related to the nature of sports activity, which would be reflected on the (physical, skill, psychological and mental) sides of players in general and players in high competition levels in particular, where improvement and superiority are very simple.

The theory of Biorhythm depends on the fact that man, from birth to death, undergoes three (mental, physical and emotional) cycles. The physical cycle requires (23) days to complete, while the emotional cycle requires (28) days to complete, and the mental cycle requires (33) days to complete (31:45).

These three cycles begin from scratch on birth and increase gradually till they reach their value. These cycles are like the wave the first half of which consists of the positive level through to the maximum point while the second half represents the negative level through to the lower point which is called the critical days per cycle. (21:60)

Ali Fahmy Al Bek (1990), Youssef Dahab Ali (2002), Ahmed Mahmoud Ibrahim et al (2014), agree that each court begins from scratch and gradually increases till they reach their apex (according to Dynos curve. They indicated that this is done on the $\left(11.5^{\text {th }}\right)$ for 
the physical cycle, $\left(14^{\text {th }}\right)$ day for the emotional cycle, and $\left(16.5^{\text {th }}\right)$ day for the mental cycle. The negative stage begins to decrease till it reaches zero, then another positive stage begins. Therefore, we find that the cycles are like waves. The first half of cycles consists of the positive level through which the cycle reaches the maximum point, while the second half represents the negative level through which the cycle reaches the lowest point of activity of cycles. The areas of intersection of cycle with the horizontal straight line, so they are called critical days per cycle. (11), (24), (8).

Ahmed Mahmoud Ibrahim and Amer Allah Ahmed (1999) note that Biorhythm is very important and effective on the physical determinants and that it is related to the efficiency of biological systems in the human body and their ability to work over the full day and the importance of this for the sports activity in general. Within the development of new approaches for training, scientific studies and researches try to determine the key functional and physical- skill requirements required for the properties of sports activity to be exercises. In addition, it positively affects the training process to reach the high sports levels.

The researcher (2007 AD) agrees with the notes of Ahmed Mahmoud Ibrahim (2005) on the Kumite competitions in karate that they are competitions of continuous development and upgrade based on scientific and applied study in the (physical, skill, psychological, mental and tactical levels). The tactical styles performed by player vary in the different situations of competition and they vary in their content and performance from player to the other and those performed by means of attack and defense. They are the essence of karate and they rank the first in attention of experts to this sport, particularly after the new amendments to the articles of the law of karate. Work and planning adds to the upgrade of Egyptian players' standard to meet the international standards of karate represented in the increasing tactical building of players in accordance with the variable situations of the games, attention to physical building in accordance with the training developments, increase of the skill building in accordance with the nature of the game. (1) and (2)

Attack performance of Kumite players and motor capacities are key approaches of sports training of players of high standards because they are new approach to upgrade the player's 
productivity and increase the player's attack performance during the games.

The researcher agrees with the notes of Ahmed Ibrahim (2011 AD) in that practical application of attack performance and its motor capacities in the training programs directed to kumite players requires scientific codification of that firstly tends to develop the motor skills of the skill styles that comprise the attack performance such as the rapid motor response, speed force, speed endurance, performance endurance and agility, and rating directed secondly to the determinants of attack performance itself as a position for attack readiness and the positions of attack applied, place division of the areas and spaces of field and time division of attack activity during the games and effect of the attack performance in terms of the points calculated in games. (3)

Therefore, the researcher believes in the importance of Biorhythm that appears in that it creates a new style of sports training in accordance with the curve of Biorhythm to upgrade the training condition of players. This is in agreement with the principle of individual differences in sports training for players through the direction of training loads in accordance with the significance of the monthly Biorhythm curves that represent the building block of the proposed training program in accordance with the values of determinants of the Biorhythm curve of player and the player's ability to perform to contribute to the upgrade of motor capacities and the skill styles of players. Therefore, the effect of attack performance determinants improves and subsequently improve the results of games and achievement of sports achievements.

\section{Aim of the research:}

This research aims at identifying the development of tactical performance determinants with the significance of monthly vital performance indicators and their effect on the results of Kumite games in karate.

\section{Hypotheses:}

1) There are differences between the effectiveness of post measurement of the levels of motor capacities of tactical performance without use and with use of the monthly Biorhythm curves in the training program of sample of the research for the favor of the post measurement using the monthly Biorhythm curvatures under research.

2) There are differences between the values of post measurement effectiveness of the levels of tactical performance without use 
and with use of the monthly Biorhythm curves in the training program for sample of the research for the favor of the post measurement using the monthly Biorhythm curvatures under research.

3) There are differences between the values of effectiveness of post measurement in the results of games with out use and with use of the monthly Biorhythm curves in the training program of the sample of the research for the favor of post measurement using the monthly Biorhythm curvatures under research

\section{Terms:}

\section{Biorhythm:}

The changes that occur to the emotional, physical and mental condition of the individual and that is related to the mechanisms and changes of the surrounding interior and exterior medium. (164:22)

\section{Procedures of the research:}

Methodology of the research:

The researcher used the experimental methodology with the post and pre design of one player because it is suitable to the nature of the research.

\section{Sample of the research}

The researcher selected the sample of the research on purposeful basis of the first league players of men for the sports season (2015 AD) in Menoufiya Karate Zone. The total sample was (20) players who were divided into the experimental sample of the research that consists of (1) player of the national team of Egypt (weight: $+84 \mathrm{~kg}$ ) to conduct the main study. The pilot group consisted of (19) players to find the scientific treatments of tests under research and use them in the experimental games under study.

\section{Consistency of the sample of the research}

Consistency of the (basic and experimental) sample of the research was conducted in the variables of (age, height, training life) and the special motor capacities under research. Table (1) indicates this to confirm that the members of the same fall under the moderate curve. 
Table (1)

Consistency of the Sample of the (Main, Pilot) Research in the variables of (age, height, training life) and motor capacities of the attack performance under research

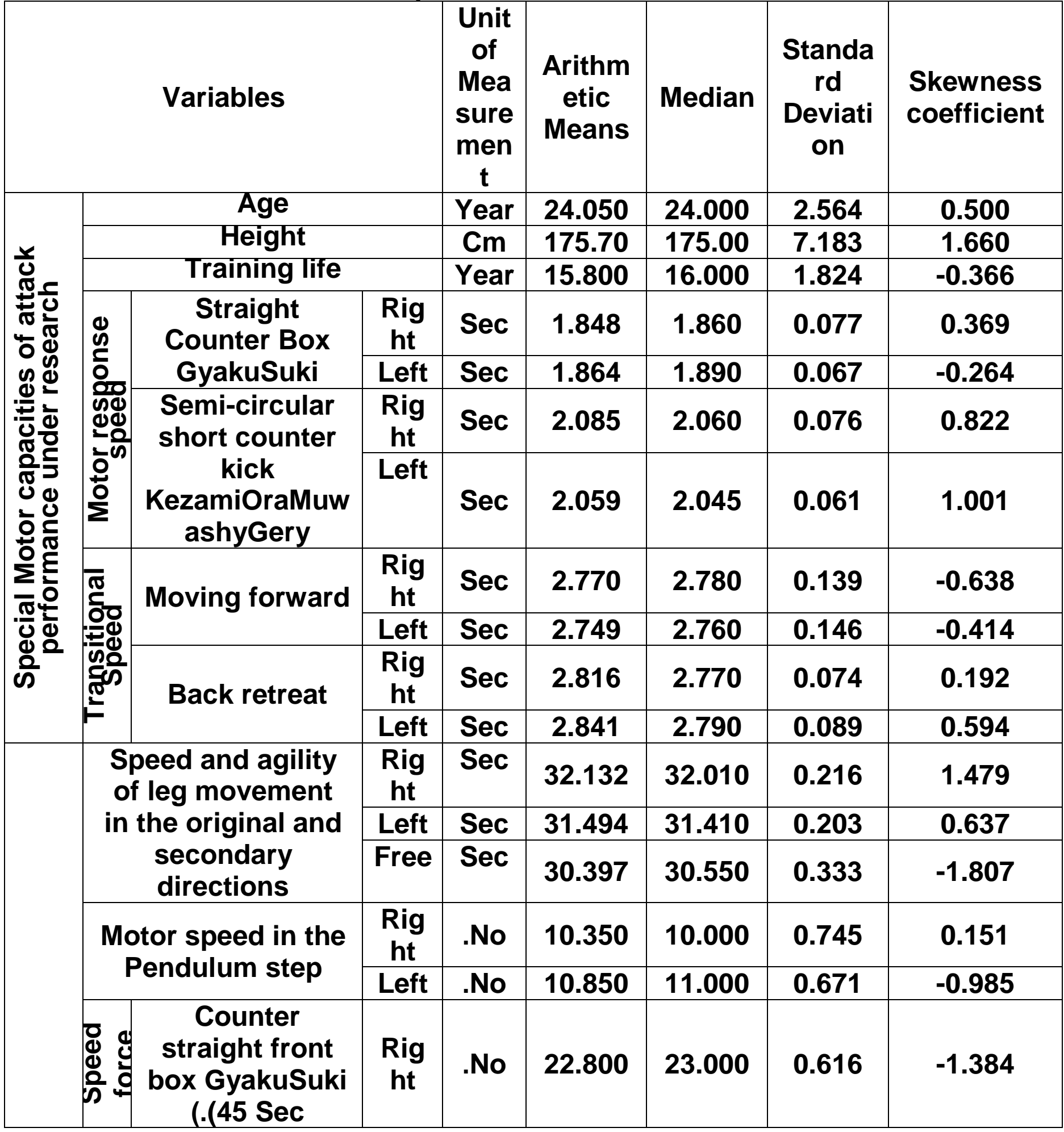




\begin{tabular}{|c|c|c|c|c|c|c|c|}
\hline & $\begin{array}{c}\text { Semi-circular } \\
\text { short counter } \\
\text { kick } \\
\text { KezamiOraMuw } \\
\text { ashyGery (10 } \\
\text { Sec.) }\end{array}$ & Left & .No & 10.950 & 11.000 & 0.510 & -0.112 \\
\hline \multirow{2}{*}{ 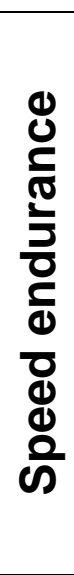 } & $\begin{array}{c}\text { Counter } \\
\text { straight front } \\
\text { box GyakuSuki } \\
\text { (.(20 Sec }\end{array}$ & $\begin{array}{c}\text { Rig } \\
\text { ht }\end{array}$ & .No & 41.050 & 41.000 & 0.510 & 0.112 \\
\hline & $\begin{array}{c}\text { Semi-circular } \\
\text { short counter } \\
\text { kick } \\
\text { KezamiOraMuw } \\
\text { ashyGery(20 } \\
\text { Sec.) }\end{array}$ & Left & .No & 20.200 & 20.000 & 0.768 & 1.178 \\
\hline \multirow{2}{*}{ 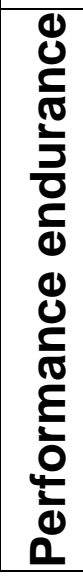 } & $\begin{array}{c}\text { Counter } \\
\text { straight front } \\
\text { box GyakuSuki } \\
\text { (.45 Sec.) }\end{array}$ & $\begin{array}{c}\text { Rig } \\
\text { ht }\end{array}$ & .No & 69.700 & 70.000 & 1.302 & -0.013 \\
\hline & $\begin{array}{c}\text { Semi-circular } \\
\text { short counter } \\
\text { kick } \\
\text { KezamiOraMuw } \\
\text { ashyGery (45 } \\
\text { Sec.) }\end{array}$ & Left & .No & 35.350 & 35.000 & 0.813 & 0.541 \\
\hline
\end{tabular}

The above table (1) indicates that the Skewness coefficients of the variables of Age ،Height ،Training life, (Special Motor capacities of attack performance under research ranged between 1.660: 1.807 is the previous samples; that is, they were limited between $( \pm 3)$

Means used for data collection:

- Physical tests of attack performance of arms under research

- Test of motor response speed in the Kumite players in Karate.

- Test of progress and retreat for measurement of transitional speed with front and back leg movement of the Kumite players in karate.

- Test of the original and secondary directions to measure speed and agility of leg performance.

- Test of the pendulum step of stability to measure the speed of movements of Kumite players in the sports of karate. 
- Test of counter straight box (GyakuSuki) and semi-circular kick skill (KezamiOraMuwashyGery) in experimental time (10 sec, 20 $\mathrm{sec}, 45 \mathrm{sec}$.) to measure speed force, speed endurance and performance endurance of skill respectively in the sample of the research. (Attachment 2).

Scientific treatments of the motor capacities under research Credibility of the tests under research

Credibility of tests under research was calculated by partitioning of liquidation between the lower spring and higher spring of pilot sample of (19 players), and the least calculated $T$ values were $(2,309)$, while the tabulated $(T)$ value at freedom of $(8)$ and significance of $(0.05)$ was $(22,695)$ which signifies the credibility of tests and their ratification as a means of evaluation and measurement.

\section{Stability of tests under research.}

Stability of tests under research was measured by application of tests and reapplication of them again (Test-Retest) with difference of (7) days between the applications of pilot sample of (19) players. The correlation coefficient between the first and second applications was calculated using the Person's simple correlation coefficient where the calculated $(r)$ value ranged between (0.824: 0.998). these represent high values, which indicates that these tests under research are highly stable and acceptable, and they were approved as a means for measurement and evaluation.

\section{Proposed training program:}

- The training programs were conducted for the first time on players of the sample of the research without use of the Biorhythm curves in the period from Thursday, 30/10/2014 to Tuesday, 09/12/2014 AD.

- The training program was conducted for the second time on the player the sample of the research using the curves of Biorhythm in the period from Monday, 22/12/2014 to Saturday, 31/01/2015 AD, and the indicators of the monthly rhythm curve of player during that period were as follows: 


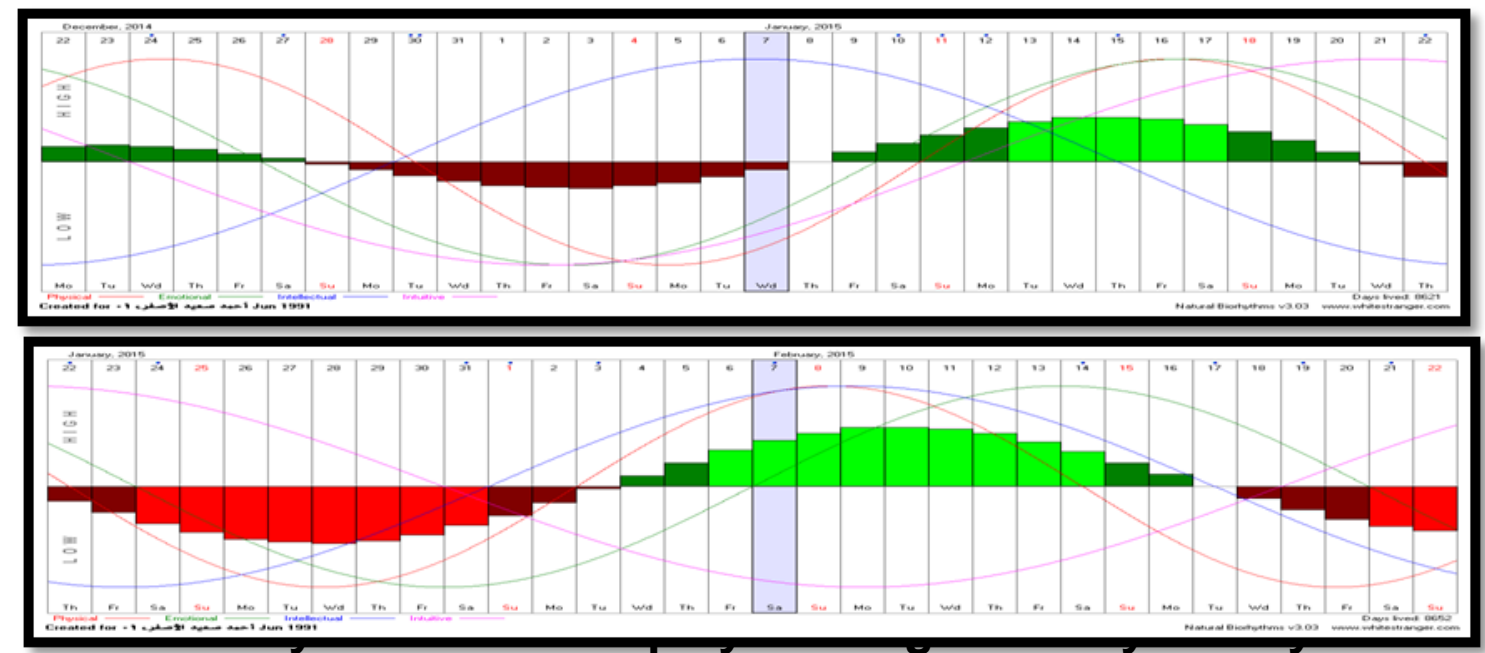

calculator v3.00, FROM 22/12/2014 TO 31/01/2015 AD

\begin{tabular}{l|l|l}
\hline \hline No. & \multicolumn{1}{|c}{ Variables } & \multicolumn{1}{c}{ Content } \\
\hline \hline & $\begin{array}{l}\text { Overall time of the } \\
\text { program }\end{array}$ & $(3150$ minutes $)=(52.5)$ training hours \\
\hline Stages of the program & $\begin{array}{l}\text { (special, before competitions) The } \\
\text { program was applied twice. The first time } \\
\text { without use and the second time with use } \\
\text { of the player's monthly biorhythm curves. }\end{array}$ \\
\hline $\begin{array}{l}\text { Time of training module } \\
\text { modules during the } \\
\text { program }\end{array}$ & $\begin{array}{l}\text { The time of training module ranges from } \\
(90: 120) \text { minutes }\end{array}$ \\
\hline $\begin{array}{l}\text { Number of training } \\
\text { modules during the week }\end{array}$ & (30) training modules \\
\hline & Number of weeks & $\begin{array}{l}\text { (6) weeks, including (4 weeks) during the } \\
\text { stage of special preparation, (2 weeks) } \\
\text { during the pre-competition stage }\end{array}$ \\
\hline \hline
\end{tabular}

Table (3) 
General Time distribution of the parts of proposed training program under research

\begin{tabular}{|c|c|c|c|c|c|}
\hline No & \multicolumn{2}{|c|}{ Parts of training module } & $\begin{array}{c}\text { percentage } \\
\text { to total } \\
\text { time }\end{array}$ & $\begin{array}{c}\text { Total } \\
\text { time in } \\
\text { minutes }\end{array}$ & $\begin{array}{l}\text { Total time } \\
\text { in hours }\end{array}$ \\
\hline 1 & \multicolumn{2}{|c|}{$\begin{array}{c}\text { Preparatory part (warm } \\
\text { up) }\end{array}$} & $10 \%$ & $320 \mathrm{~min}$ & $\begin{array}{l}5.333 \\
\text { Hour }\end{array}$ \\
\hline \multirow{4}{*}{2} & \multirow{4}{*}{$\begin{array}{l}\frac{1}{\pi} \\
\frac{2}{2} \\
\frac{c}{\pi} \\
\sum\end{array}$} & $\begin{array}{c}\text { Special physical } \\
\text { preparation }\end{array}$ & $20 \%$ & 640Min & $\begin{array}{c}10.666 \\
\text { hour }\end{array}$ \\
\hline & & Year & $13 \%$ & 416 Min & $\begin{array}{l}6.933 \\
\text { Hour }\end{array}$ \\
\hline & & $\begin{array}{l}\text { Attack tactical } \\
\text { preparation }\end{array}$ & $30 \%$ & 960Min & 16 Hour \\
\hline & & $\begin{array}{c}\text { Competition } \\
\text { exercises }\end{array}$ & $22 \%$ & 704 Min & $\begin{array}{l}11.733 \\
\text { Hour }\end{array}$ \\
\hline \multirow[t]{2}{*}{3} & & Final & $5 \%$ & 160 Min. & $\begin{array}{l}2.666 \\
\text { Hour }\end{array}$ \\
\hline & & Total & $100 \%$ & $3200 \mathrm{Min}$ & $\begin{array}{l}53.333 \\
\text { Hour }\end{array}$ \\
\hline
\end{tabular}

Proposed training loads during the proposed training modules:

The training program was applied using the periodic training approach of high and low intensity and repetitive program. The daily training module consisted of three parties (preparatory, main, final).

First: Preparatory (warm up) part:

Warm up includes the light running exercises, muscle preparation exercises, general stimulation of blood circulation, stretch exercises, and some exercises that contribute to raise body temperature where the organs and neurological and physiological parts of the body become ready to admit the content of training module. In addition, the body flexibility exercises and concentration of them for rapid recovery of the effects of technical exercises that precede the physical exercises directly, and preparation of them to prepare the content of the main part, raise their capacities and direct the content of that stage to anerobic work. The load ranges between $(40: 45 \%)$ of the maximum capacity of the player. The total time of 
this section was (320) minutes; that is, $(10 \%)$ of the total time of the proposed program under research.

\section{Second: Main Part:}

This part consists of four different sections (exercises of special physical preparation, exercises of skill preparation, exercises of tactical preparation and exercises of competitive preparation). The total time of this section was (2720 minutes); that is, (85\%) of the total time of the proposed training program under research.

The research used the maximum, less than maximum and moderate training loads with their degrees of (9: 100, 75: 90, 50: $75 \%)$ respectively, from the highest intensity using the high and low periodic exercise methods, low intensity and repetitive training methods.

\section{Section one: special physical preparation exercises}

This section includes the physical training exercises for development of motor capacities of tactical performance under research. The motor response speed, motor speed, transitional speed and speed force of the arms and legs, speed endurance, speed and agility of leg movement for the different skills of attack by arms and single and compound arms and legs from the position of right and left attack readiness with types of direct attack and counter attack. Intensity of training load used in this section ranges between

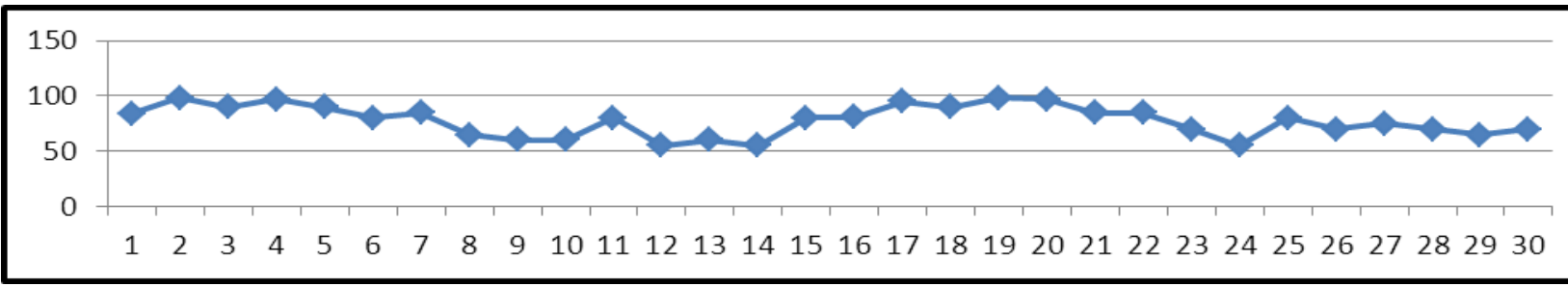

$(55 \%)$ to $(98 \%)$ of the maximum performance of each player. The total time of this section was (640 minutes)I that is, (20\%) of the total time required for the proposed program under research.

Figure (2) intensity of daily training load for the physical preparation under research

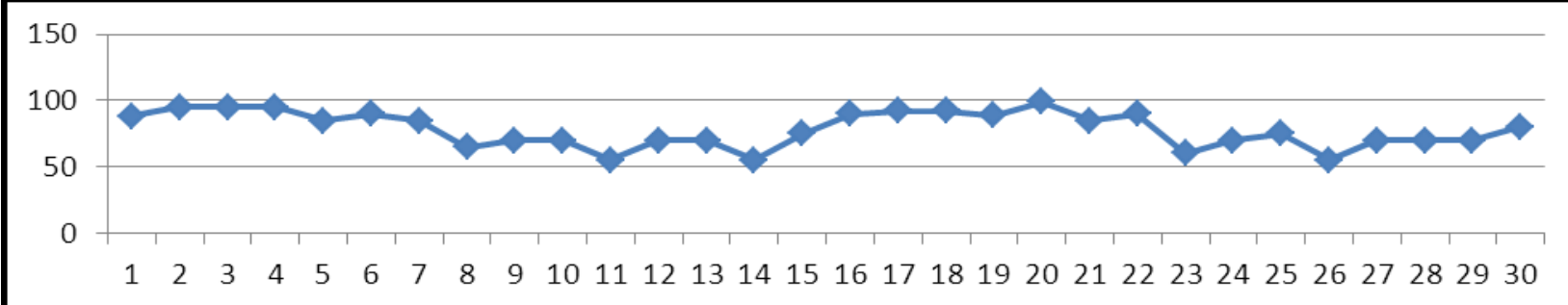




\section{Section two: Skill preparation exercises}

The total time of this section was (416 minutes); that is (13\%) of the total time of the proposed program (55\%: $98 \%$ ) of the maximum intensity for player. This part includes training of arms and legs skill for the player's performance of single and combined skills of the arms or legs only, and combined skills using the arms and legs.

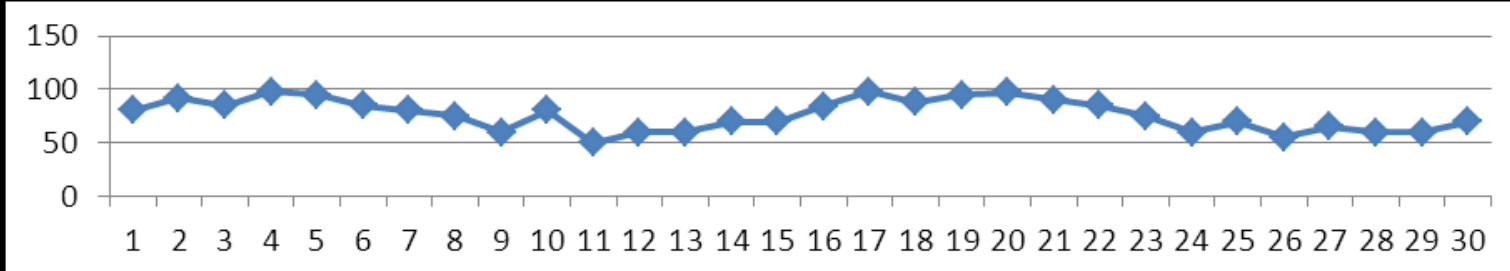

Figure (4) intensity of daily training load for tactical preparation under research

Section three: exercises of tactical preparation:

The total time of this section was (960 minutes); that is, $(30 \%)$ of the total time of the proposed program under research. The intensity of training load durign this section ranged from (55\%: $98 \%$ ) of the maximum intensity for player. This training section includes the single and combined arms and legs attack skills, including training through the different tactics of playing by use of the types of direct attack and counter attack after training in them without peer, then with negative peer, stable positive peer and moving positive peer.

\section{Section four: Competitive preparation (game training)}

The total of this part was (704) minutes with percentage of $22 \%$ of the total time of training program under research. This section includes the conditional training exercises and experimental competition exercises under research. The conditional exercises are based on conditions to be defined by trainer through the modules of training program in accordance with the purpose of training. It may be conditional upon the area of playing or time of game $(10,20,30$, 45 and 60 ) or more seconds. It may be conditional upon the skills and their type (arms, legs, mixed) individual or composite, or by definition of the type of attack used whether direct attack or type of counter attack under research. The trial games are games for real free application of player and training in it is usually provided through the modules of training program. 


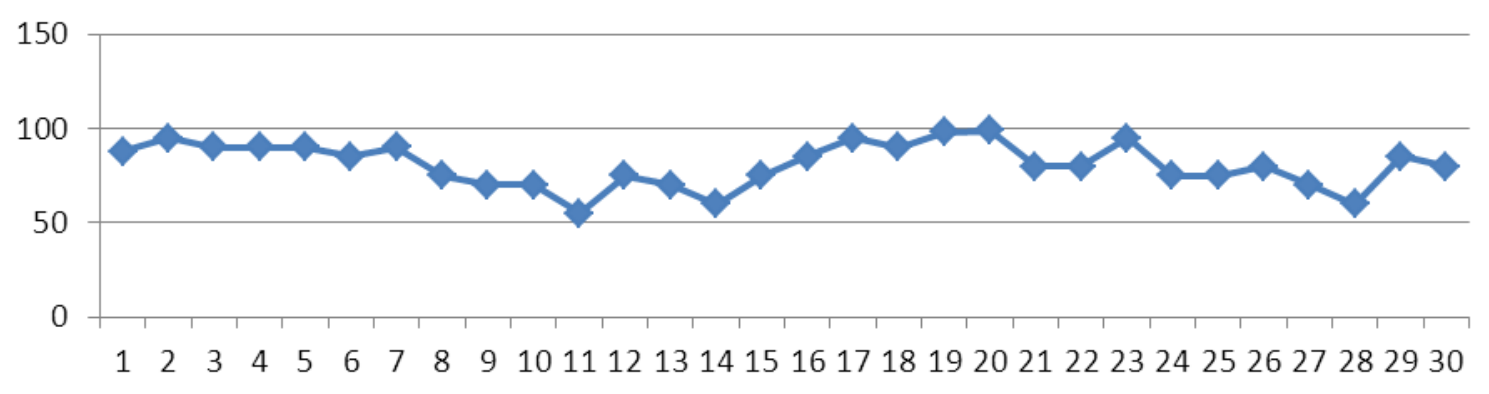

Figure (5) intensity of daily training load of competitive exercises (game training)

\section{Final part}

This part contains the warm down exercises that help recovery of the daily training load in accordance with the aerobic energy systems. Intensity of training used during this part ranges from (35\%: $40 \%$ ) of the maximum intensity of player. In addition, the total time of this section was (160) minutes; that is, with percentage of $(5 \%)$ of the total time of the proposed program under research.

\section{Implement steps of the research}

\section{Scientific treatments}

- The first application was made to the motor capacities tests under research on Wednesday, 15/10/2014 AD.

- The second application was made to the special motor capacity tests under research on Thursday, 23/10/2014 AD.

- Form of the attack performance analysis under research during the period from 15/10/2014 to 23/10/2014 AD.

\section{Post measurement:}

- Post measurement was done on Monday, $27 / 10 / 2014$ in (5) trial matches of the players the sample of the research.

- The post measurement was done on Thursday, 28/10/2014 in the special motor capacity test under research. 
Application of training program without use of biorhythm curve.

- The training program was applied from Thursday, 30/10/2014 to Tuesday, 09/12/2014 AD

Post measurement of the training program without use of the biorhythm curves.

- The second measurement was done on Monday and Tuesday, $15,16 / 12 / 2014$ on the same conditions and standards of the post measurement.

Application of the training program using the biorhythm curves

- The training program was applied from Monday, 22/12/2014 to Saturday, 31/01/2015 AD.

Post measurement of the program using the biorhythm curves

- Post measurement was used on Monday and Thursday, 2, $3 / 02 / 2015$ on the same conditions and standards of post measurement.

\section{Statistic treatment}

The SPSS program was used to statistically treat the data, and the following statistic means were applied:

- Arithmetic Means.MedianMode.

- Standard DeviationStandard Deviation.

- Skewness coefficient

- Pearson's Simple Correlation Coefficient.

- Improvement rates in percentages

Statistic significance of $(0.05)$. The research was satisfied with the results. 
Article (5)

Differences and percentage of improvement between the post and pre measurement in the level of special motor capacities under research for the training program without use of biorhythm curves

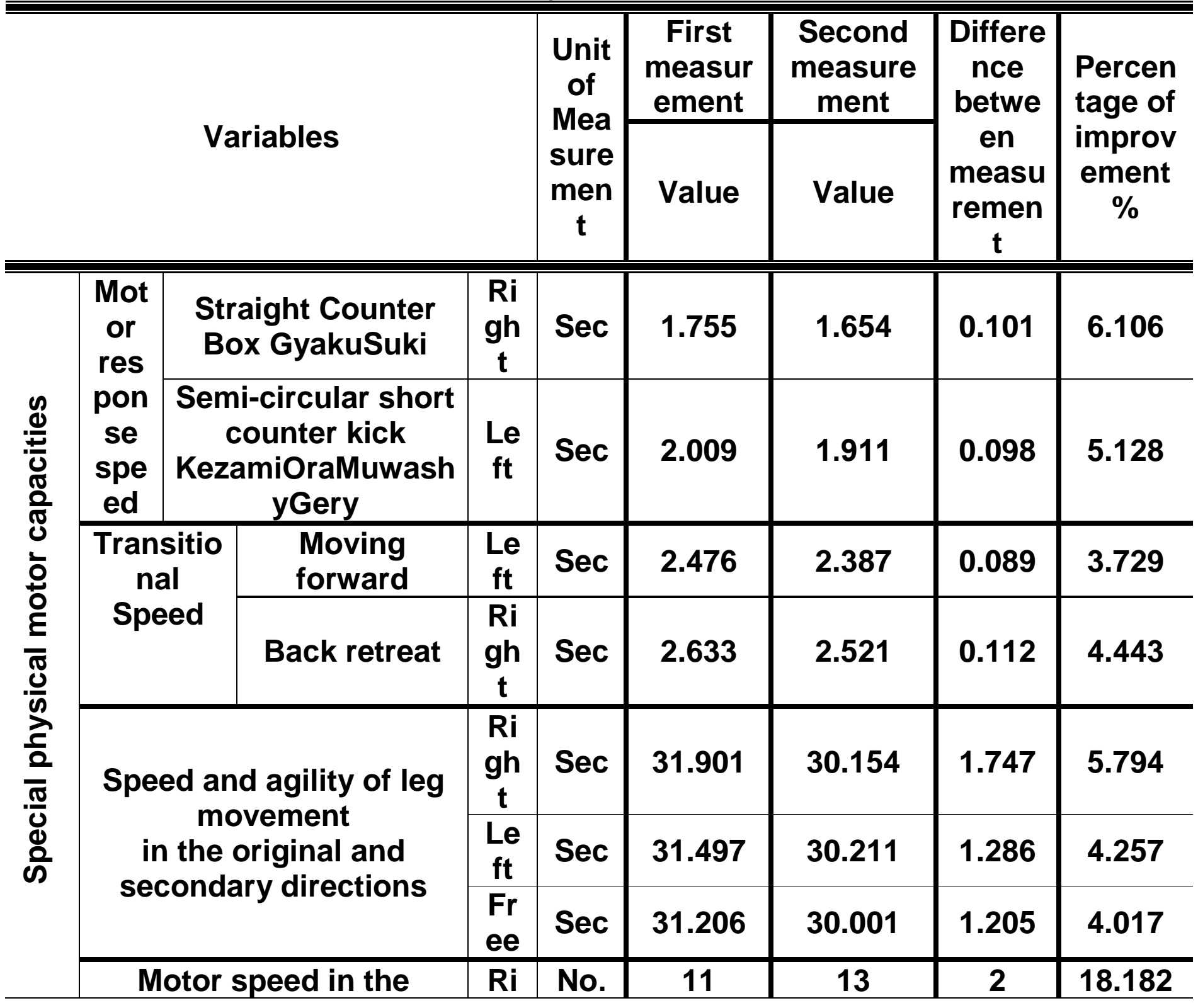




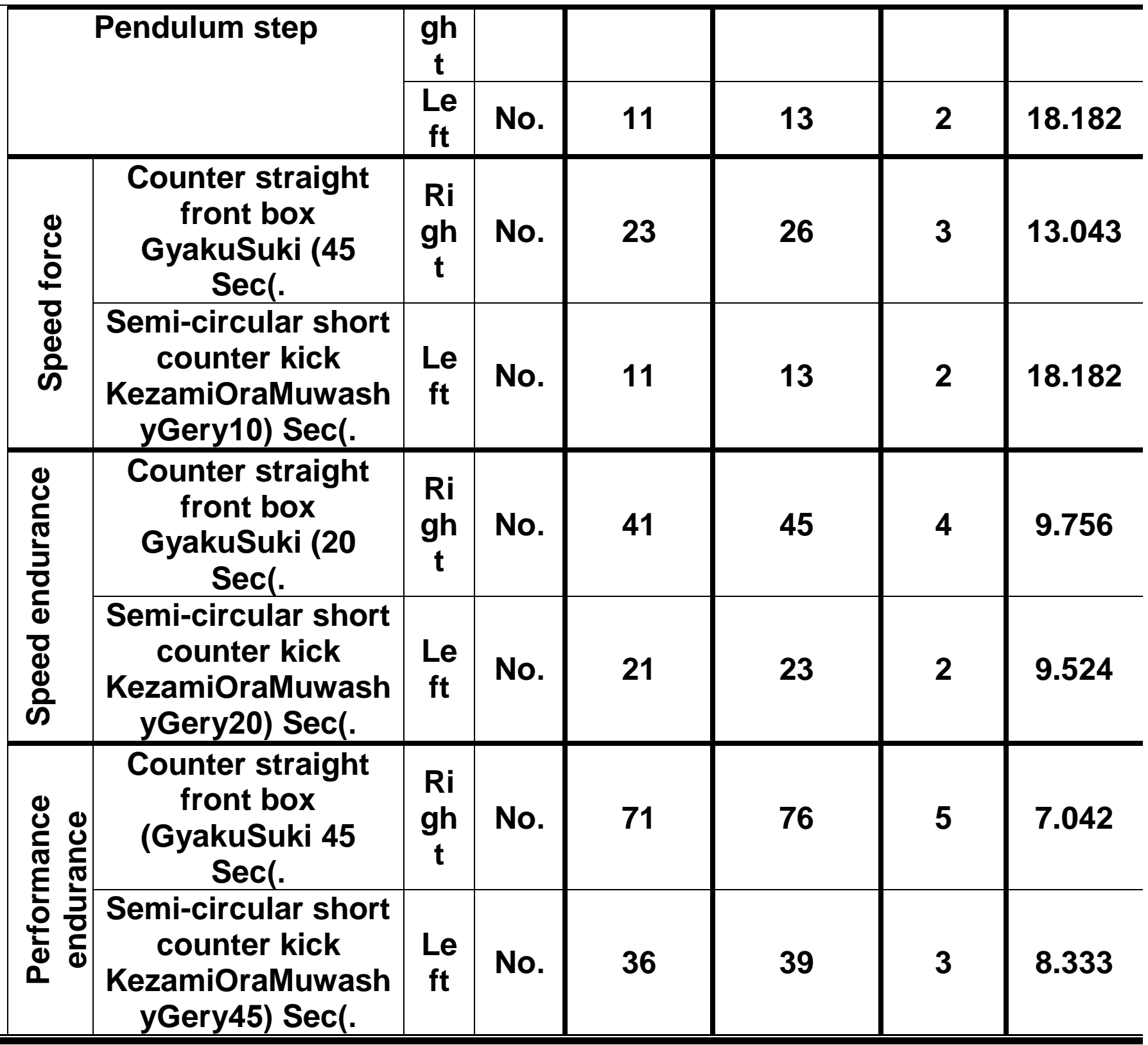

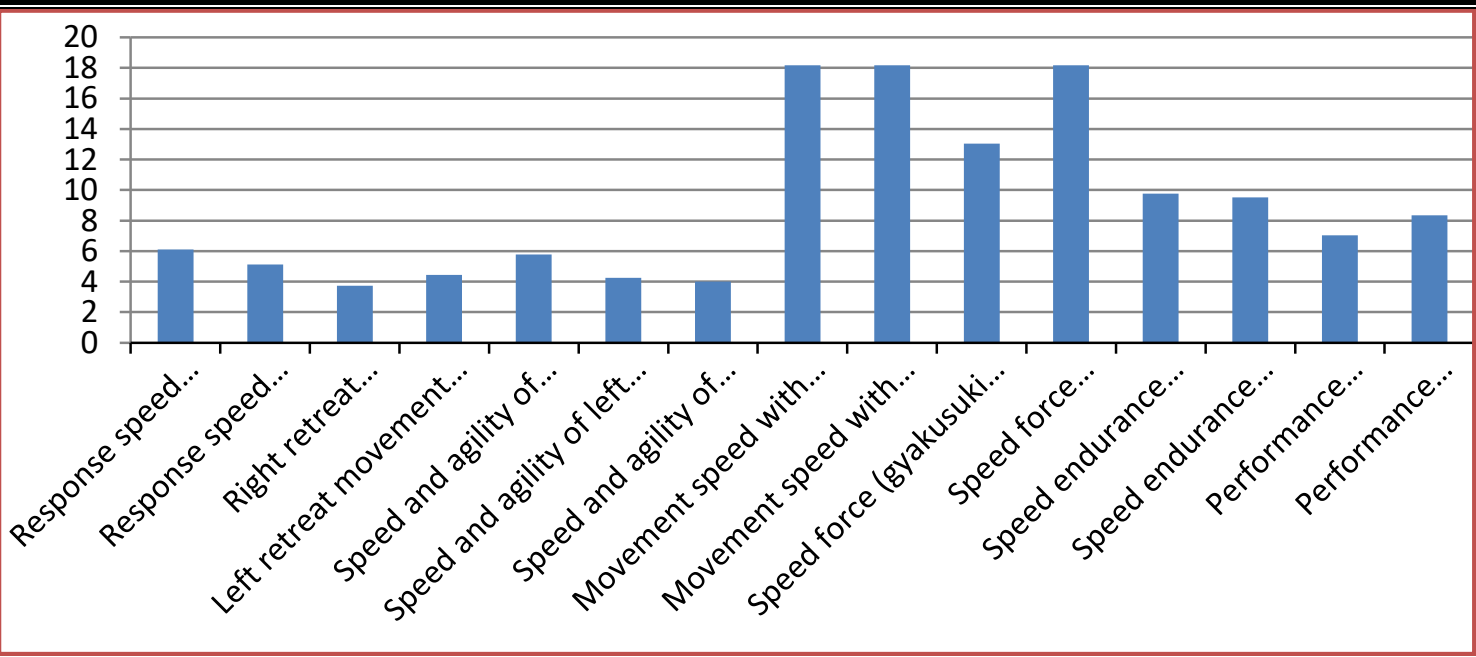


Table (6)

Differences and percentages of improvement between the post measurement without use and with use of the biorhythm curves of player in the level of special motor capacities under research

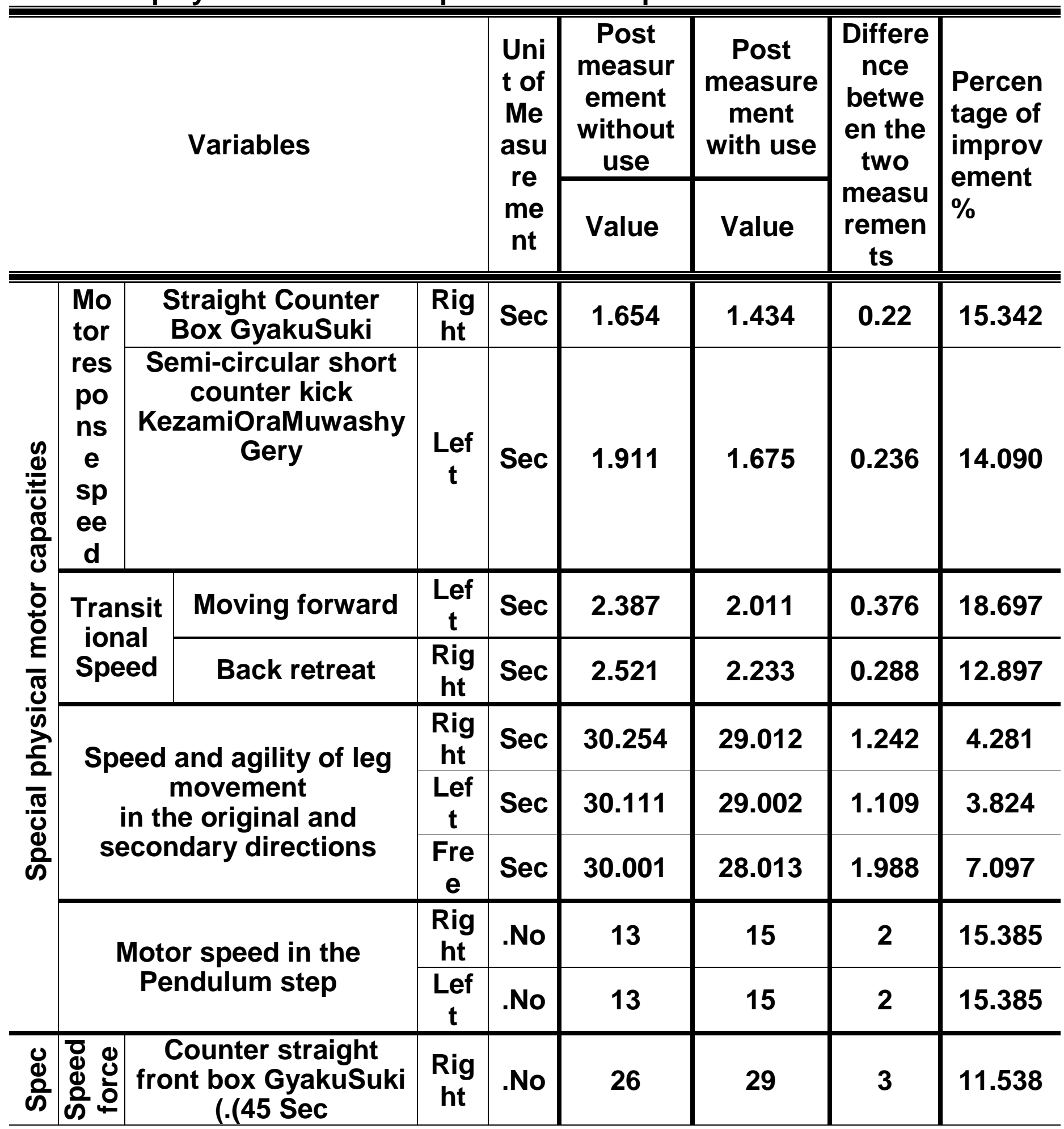




\begin{tabular}{|c|c|c|c|c|c|c|c|}
\hline & \begin{tabular}{|c|} 
Semi-circular short \\
counter kick \\
KezamiOraMuwashy \\
$($. Sec10)Gery \\
\end{tabular} & $\begin{array}{c}\text { Lef } \\
t\end{array}$ & .No & 13 & 15 & 2 & 15.385 \\
\hline \multirow{2}{*}{ 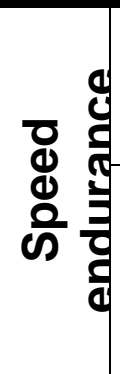 } & $\begin{array}{c}\text { Counter straight } \\
\text { front box GyakuSuki } \\
(.(20 \text { Sec }\end{array}$ & $\begin{array}{c}\text { Rig } \\
\text { ht }\end{array}$ & .No & 45 & 51 & 6 & 13.333 \\
\hline & $\begin{array}{c}\text { Semi-circular short } \\
\text { counter kick } \\
\text { KezamiOraMuwashy } \\
(. \text { Sec20)Gery }\end{array}$ & $\begin{array}{c}\text { Lef } \\
t\end{array}$ & .No & 23 & 26 & 3 & 13.043 \\
\hline \multirow{2}{*}{ 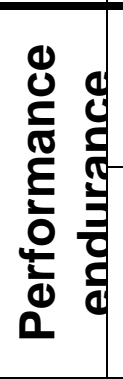 } & $\begin{array}{c}\text { Counter straight } \\
\text { front box } \\
\text { (.(GyakuSuki } 45 \mathrm{Sec}\end{array}$ & $\begin{array}{c}\text { Rig } \\
\text { ht }\end{array}$ & .No & 76 & 84 & 8 & 10.526 \\
\hline & $\begin{array}{l}\text { Semi-circular short } \\
\text { counter kick } \\
\text { KezamiOraMuwashy } \\
\text { (. Sec45)Gery }\end{array}$ & $\begin{array}{c}\text { Lef } \\
t\end{array}$ & .No & 39 & 43 & 4 & 10.256 \\
\hline
\end{tabular}

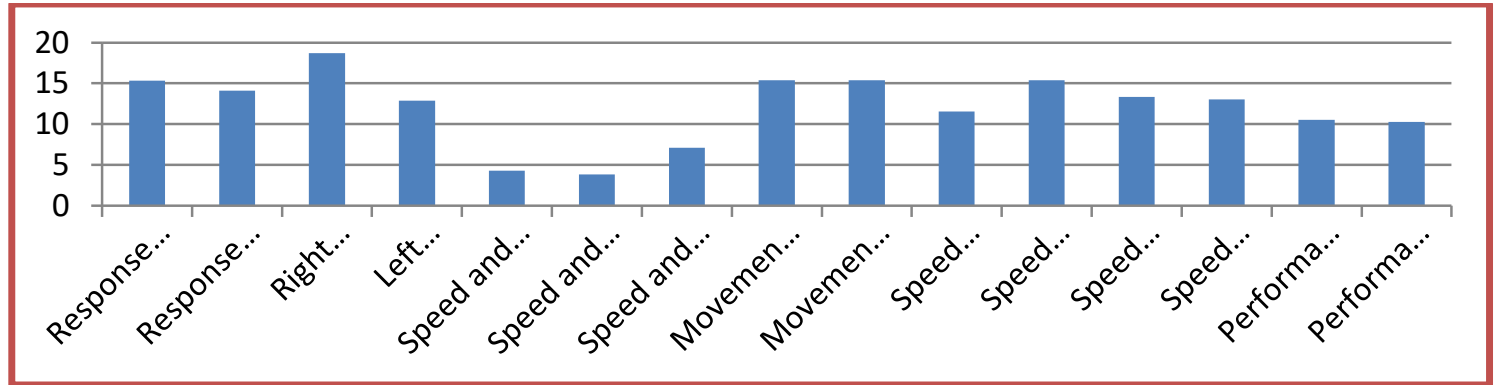

Figure (7) Percentage of improvement of post measurement without use and with use of biorhythm curves in the training program under research

Tables (5 and 6) and figures (6 and 7) indicate differences in the values of test of special motor capacities with the tactical attack performance of the player the sample of the research between the pre measurement and post measurement of the first training program without use of the biorhythm indicators, and the post measurements of the training program without use of the indicators of biorhythm and post measurement of the training program using the indicators of monthly biorhythm for the player the sample of the research. The lowest and higher values of differences were (0.069: 5.000) and (0.22: 6) and the least and highest percentage of 
improvement $(3,729,18,182 \%)(3,824,18,697)$ for the favor of post measurement (without use, with use) of biorhythm indicators respectively.

In addition, there appear differences in the values of motor response speed test for the counter box- GyakoSuki (right) and the Semi-circular short counter kick- KezamiMawashiGery (Left) between the pre and post measurements of the first training program without use of the biorhythm indicator, and between the post measurement of the training program without use of the biorhythm indicators and post measurement of the training program using the monthly biorhythm indicators of the player the sample of the research. The differences of values were $(0.098,0.101),(0.222$, $0.236)$, and the percentage of improvement were $(6.106,5.128 \%)$ $(15.234,14.090 \%)$ for the favor of post measurement (with use, without use) of biorhythm indicators respectively.

There are differences in the values of transitional speed forward and (right) and retreat ( back ) between the pre measurement and post measurement of the first training program without using the biorhythm indicator and post measurement of the training using the monthly biorhythm indicators of the player the sample of the research. The differences of values were $(0.089$, $0.112),(0.376,0.288)$, and the percentages of improvement were $(3.729,4.442 \%),(18.697,12.897 \%)$ for the favor of post measurement (without use, with use) of biorhythm indicators respectively.

There are statistically significant differences between the test values of the original and secondary approaches of speed and agility of leg movement (free, left, right) between the pre measurement and post measurement of the first training program without using the biorhythm indicator and post measurement of the training using the monthly biorhythm indicators of the player the sample of the research. The differences of values were (1.747, $1.286,1.205),(1.242,1.109,1.988)$, and the percentages of improvement were $(5.794,4.257,4.017 \%),(4.281,3.824,7.097 \%)$ for the favor of post measurement (without use, with use) of biorhythm indicators respectively.

There are differences in the values of Motor speed in the Pendulum step(Right ، Left) between the pre measurement and post measurement of the first training program without using the biorhythm indicator and post measurement of the training using the 
monthly biorhythm indicators of the player the sample of the research. The differences of values were $(2.000,2.000),(2.000$, $2.000)$, and the percentages of improvement were (18.182, $18.182 \%),(15.385,15.385)$ for the favor of post measurement (without use, with use) of biorhythm indicators respectively.

There are differences in the speed force test values in experimental time of (10 second) for the counter box-GyakuSuki (Right) and Semi-circular short counter kick- KezamiMawashi Geri (Left) between the pre measurement and post measurement of the first training program without using the biorhythm indicator and post measurement of the training using the monthly biorhythm indicators of the player the sample of the research. The differences of values were $(2.000,3.000),(3.000,2.000)$, and the percentages of improvement were $(13.043,18.182 \%),(11.538,15.385 \%)$ for the favor of post measurement (without use, with use) of biorhythm indicators respectively.

In addition, there are differences in the values of speed endurance tests in experimental time of $(20 \mathrm{sec}$.) for the counter box- gyakusuki (right) and the semi-circular short counter kickkezamimawashigery (left) between the pre measurement and post measurement of the first training program without use of biorhythm indicators, and between the post measurement of the training program without use of biorhythm indicators and post measurement of the training program using the monthly biorhythm indicators of the sample of the research. The differences of values were (2.000, $4.000),(6.000,3.000)$, and the percentages of improvement were $(9.756,9.524 \%), \quad(13.333,13.043 \%)$ for the favor of post measurement (without use, with use) of biorhythm indicators respectively.

There appear differences in the performance endurance test values in experimental time of (45 sec.) for the counter boxgyakusuki (right) and the semi-circular short counter kick test kezamimawashigeri (left) between the pre measurement and post measurement of the first training program without use of the biorhythm indicators, and between the post measurement of training program without use of the biorhythm indicators and post measurement of the training program using the indicators of the player's monthly biorhythm indicators of the player the sample fo the research. The differences of values were $(3.000,5.000),(4.000$, $8.000)$, and the percentages of improvement were $(7.042,8.333 \%)$, 
(10.526, 10256\%) for the favor of post measurement (without use, with use) of biorhythm indicators respectively.

This improvement may be attributed to the post measurement of the first phase of the program; that is, without use of biorhythm to the training program because of the special exercises it contains for development of the special motor capacities under research.

The improvement of final or post measurement of the second phase of the training program using the biorhythm indicators for the post measurement of the first phase of the program into formation of the training loads of the training program in accordance with the biorhythm curves and individual rating of the player the sample of the research during the second phase of implementation of the training program under study. In addition, this improvement may be attributed to the simultaneous effect of biorhythm by rationalizing the properties of training loads directed to the special motor capacities under study that contributed to the positive effect and improvement in the second phase of the program. This agrees with the notes of Haddad, M et al (2011); Emad AI Sersy (2011 AD); Omar Labib (2002 AD); Ibrahim Al Ebiary (2007); Mohamed Ali ABdelrahman (2009, 2013 AD); Heba Mohamed Ali Hassan (2012 AD); Wael Hassan Abu El Khir (2014); Moataz Abu Esaad (2014 AD). (29), (5), (7), (13), (14), (1), (14, 15), (18), (6), (9), (20), (19), (17).

Table (7)

Differences and percentage of improvement of the effectiveness of tactical performance determinants for the matches of pre and post measurement without use of biorhythm indicators in the training program under research

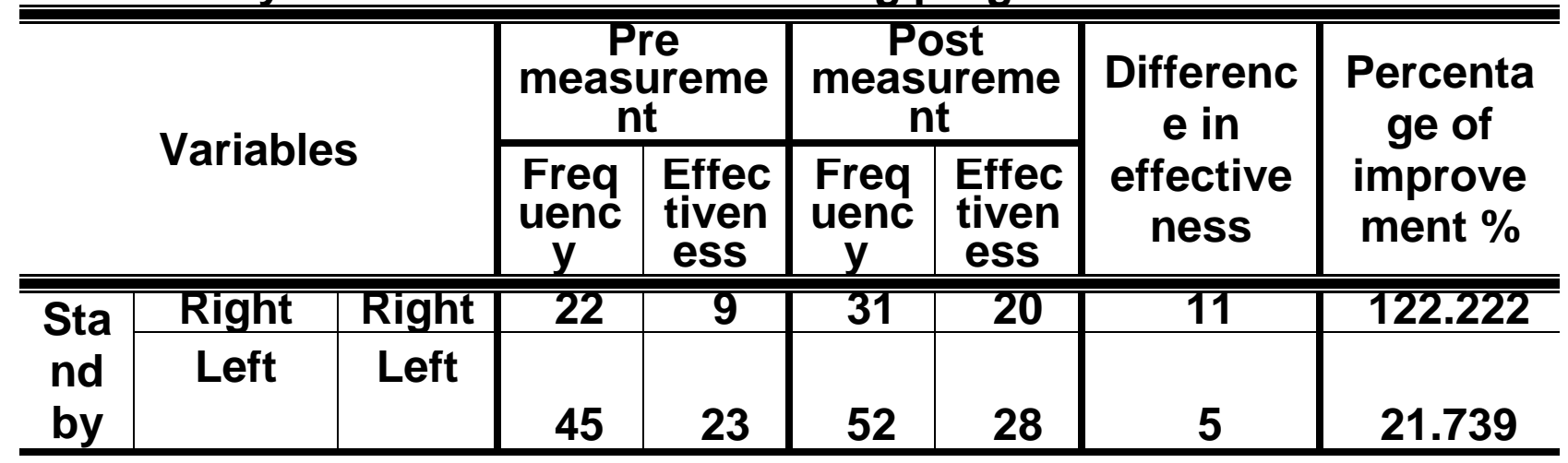




\begin{tabular}{|c|c|c|c|c|c|c|c|c|c|c|}
\hline $\begin{array}{c}\text { mo } \\
\text { de }\end{array}$ & & & & & & & & & & \\
\hline \multirow{7}{*}{ 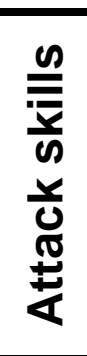 } & \multirow{7}{*}{ 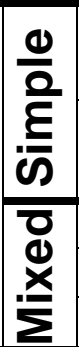 } & \multirow{2}{*}{\multicolumn{2}{|c|}{$\underset{s}{A r m}$}} & Right & 11 & 8 & 14 & 8 & 0 & 0.000 \\
\hline & & & & Left & 9 & 3 & 9 & 4 & 1 & 33.333 \\
\hline & & \multirow{2}{*}{\multicolumn{2}{|c|}{$\underset{s}{\operatorname{Leg}}$}} & Right & 2 & 2 & 8 & 4 & 2 & 100.000 \\
\hline & & & & Left & 11 & 3 & 12 & 9 & 6 & 200.000 \\
\hline & & \multicolumn{3}{|c|}{ Arms } & 75 & 8 & 78 & 12 & 4 & 50.000 \\
\hline & & \multirow{2}{*}{\multicolumn{3}{|c|}{ Legs }} & 6 & 3 & 7 & 3 & 0 & 0.000 \\
\hline & & \multicolumn{2}{|c|}{ Mixed } & & 13 & 5 & 15 & 8 & 3 & 60.000 \\
\hline \multirow{13}{*}{ 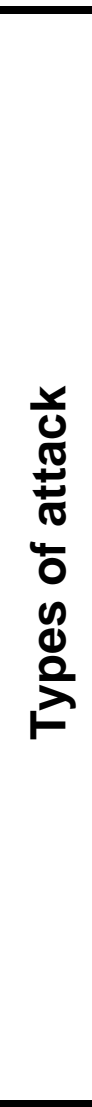 } & \multirow{2}{*}{\multicolumn{3}{|c|}{$\begin{array}{l}\text { Direct } \\
\text { attack }\end{array}$}} & $\underset{\mathrm{e}}{\operatorname{simpI}}$ & 9 & 3 & 14 & 11 & 8 & 266.667 \\
\hline & & & & $\underset{d}{\operatorname{Mixe}}$ & 7 & 6 & 11 & 9 & 3 & 50.000 \\
\hline & \multirow{2}{*}{\multicolumn{3}{|c|}{$\begin{array}{c}\text { Sen } \\
\text { no } \\
\text { sen }\end{array}$}} & $\underset{\mathrm{e}}{\operatorname{Simp}}$ & 15 & 9 & 13 & 9 & 0 & 0.000 \\
\hline & & & & $\underset{d}{\operatorname{Mixe}}$ & 2 & 1 & 3 & 1 & 0 & 0.000 \\
\hline & \multirow{9}{*}{ 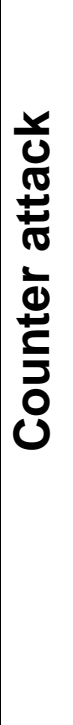 } & \multirow{2}{*}{\multicolumn{2}{|c|}{$\begin{array}{c}\text { Tai } \\
\text { no } \\
\text { sen }\end{array}$}} & $\underset{\mathrm{e}}{\operatorname{simp}}$ & 3 & 2 & 7 & 5 & 3 & 150.000 \\
\hline & & & & $\underset{d}{\operatorname{Mixe}}$ & 3 & 1 & 6 & 1 & 0 & 0.000 \\
\hline & & \multirow{2}{*}{\multicolumn{2}{|c|}{$\begin{array}{c}\text { Ta } \\
\text { tai } \\
\text { no } \\
\text { sen }\end{array}$}} & $\underset{\mathrm{e}}{\operatorname{SimpI}}$ & 2 & 1 & 3 & 2 & 1 & 100.000 \\
\hline & & & & $\underset{d}{\operatorname{Mixe}}$ & 10 & 4 & 6 & 3 & -1 & -25.000 \\
\hline & & \multirow{3}{*}{\multicolumn{2}{|c|}{$\begin{array}{c}\text { Gon } \\
\text { use } \\
\text { n }\end{array}$}} & $\operatorname{Simpl}_{\mathrm{e}}$ & 1 & 1 & 4 & 3 & 2 & 200.000 \\
\hline & & & & Mixe & 3 & 1 & 8 & $?$ & 1 & 10000 \\
\hline & & & & Simnl & & 1 & & & $I$ & 100.000 \\
\hline & & \multirow{2}{*}{\multicolumn{2}{|c|}{$\begin{array}{c}\text { Gon } \\
\text { use } \\
n\end{array}$}} & e & 3 & 1 & 2 & 1 & 0 & 0.000 \\
\hline & & & & $\underset{d}{\operatorname{MilXe}}$ & 9 & 2 & 6 & 1 & -1 & -50.000 \\
\hline \multirow{9}{*}{$\begin{array}{l}\mathscr{0} \\
\mathbb{d} \\
\frac{d}{\sigma} \\
\frac{0}{0} \\
\frac{0}{1}\end{array}$} & \multirow{3}{*}{ A } & \multirow{3}{*}{ B } & & $A$ & 5 & $\overline{2}$ & 7 & 4 & 2 & 100.000 \\
\hline & & & \multirow[t]{2}{*}{ C } & B & 6 & 2 & 9 & 5 & 3 & 150.000 \\
\hline & & & & $\overline{\mathbf{C}}$ & 4 & 1 & 7 & 4 & 3 & 300.000 \\
\hline & \multirow{3}{*}{ D } & \multirow{3}{*}{ E } & \multirow{3}{*}{$\mathbf{F}$} & D & 7 & 3 & 11 & 6 & 3 & 100.000 \\
\hline & & & & $E$ & 21 & 14 & 18 & 11 & -3 & -21.429 \\
\hline & & & & $\mathbf{F}$ & 8 & 3 & 9 & 5 & 2 & 66.667 \\
\hline & \multirow{3}{*}{ G } & \multirow{3}{*}{ H } & \multirow{3}{*}{ I } & $\mathbf{G}$ & 4 & 2 & 7 & 4 & 2 & 100.000 \\
\hline & & & & $\mathbf{H}$ & 5 & 3 & 7 & 4 & 1 & 33.333 \\
\hline & & & & I & 6 & 2 & 8 & 5 & 3 & 150.000 \\
\hline \multirow{3}{*}{$\begin{array}{c}\text { Ga } \\
\text { me } \\
\text { tim } \\
\text { e } \\
\end{array}$} & \multirow{3}{*}{\multicolumn{4}{|c|}{$\begin{array}{c}\text { First Tuesday } \\
\text { Second } \\
\text { Tuesday } \\
\text { Third Tuesday }\end{array}$}} & 19 & 8 & 25 & 13 & 5 & 62.500 \\
\hline & & & & & 22 & 13 & 31 & 15 & 2 & 15.385 \\
\hline & & & & & 26 & 11 & 27 & 20 & 9 & 81.818 \\
\hline Ga & & & aite & & 40 & 0 & 46 & 0 & 0 & 0.000 \\
\hline
\end{tabular}




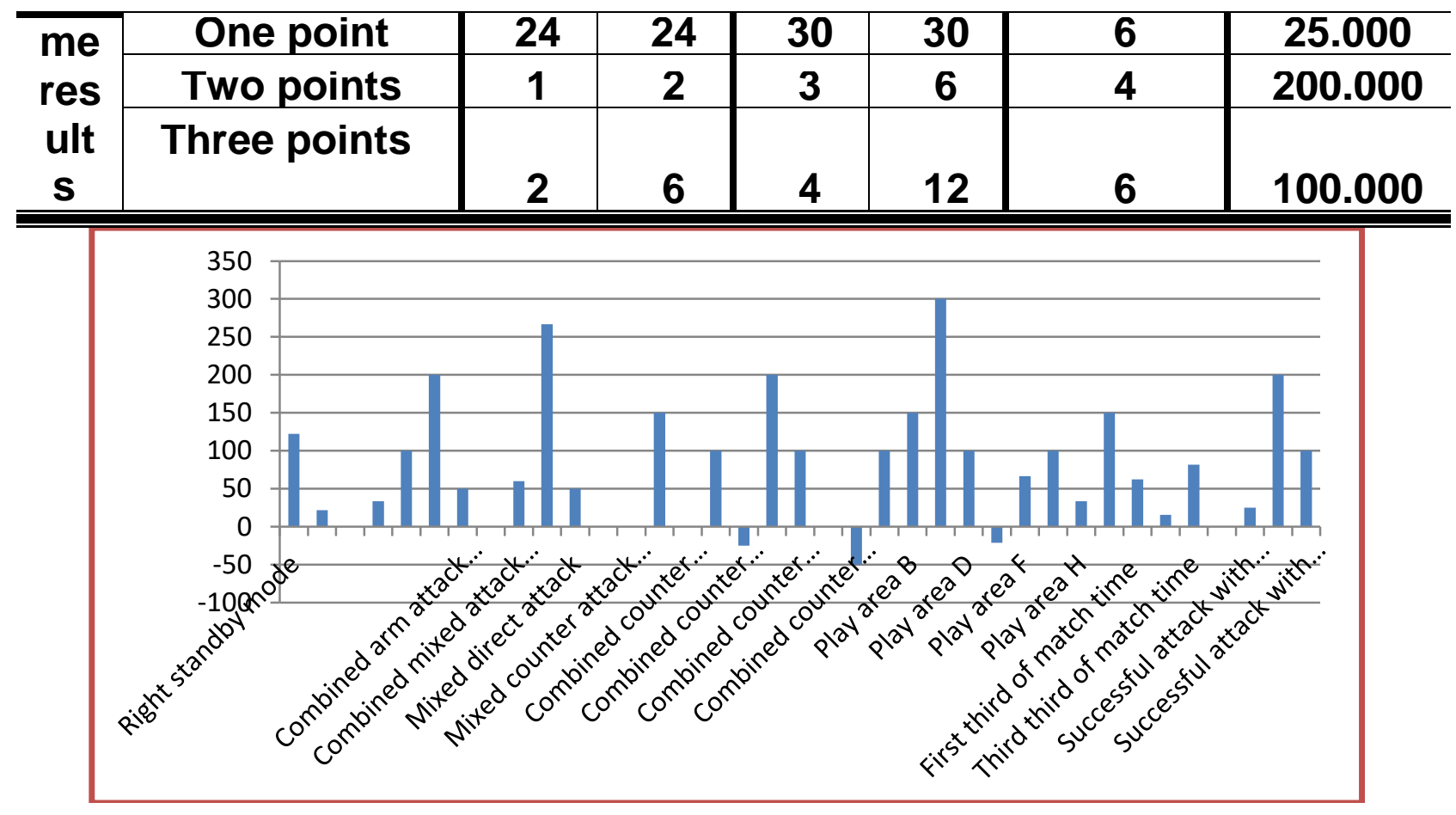

Figure (8) percentage of improvement of the effectiveness of tactical performance of the values of pre and post measurements without use of biorhythm indicators in the training program under research

Table (8/1)

Differences and percentage of improvement of the effectiveness of game results for the determinants of tactical performance of the post measurement without use and with

use of biorhythm curves in the training program under research.

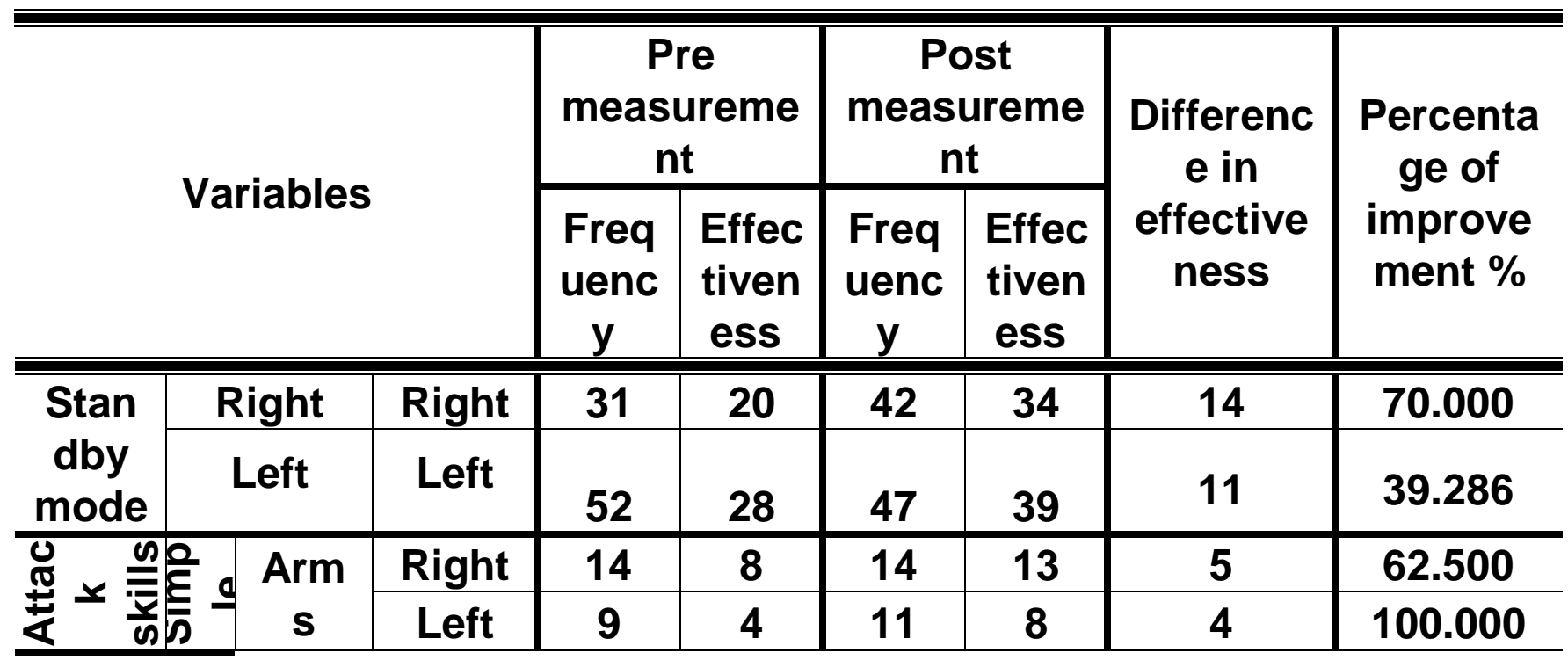




\begin{tabular}{|c|c|c|c|c|c|c|c|c|}
\hline & \multirow{2}{*}{ Legs } & Right & 8 & 4 & 7 & 6 & 2 & 50.000 \\
\hline & & Left & 12 & 9 & 14 & 11 & 2 & 22.222 \\
\hline \multirow{3}{*}{$\begin{array}{l}\mathbf{D} \\
\underset{\mathbf{x}}{\mathbf{z}} \\
\end{array}$} & \multicolumn{2}{|c|}{ Arms } & 18 & 12 & 23 & 19 & 7 & 58.333 \\
\hline & \multicolumn{2}{|c|}{ Legs } & 7 & 3 & 11 & 9 & 6 & 200.000 \\
\hline & \multicolumn{2}{|c|}{ Mixed } & 15 & 8 & 9 & 7 & -1 & -12.500 \\
\hline
\end{tabular}

Table (8 /2)

Differences and percentage of improvement of the effectiveness of game results for the determinants of tactical performance of the post measurement without use and with use of biorhythm curves in the training program under research.

\begin{tabular}{|c|c|c|c|c|c|c|c|c|c|}
\hline \multirow{2}{*}{\multicolumn{4}{|c|}{ Variables }} & \multicolumn{2}{|c|}{$\begin{array}{c}\text { Pre } \\
\text { measureme } \\
\text { nt }\end{array}$} & \multicolumn{2}{|c|}{$\begin{array}{c}\text { Post } \\
\text { measureme } \\
\text { nt }\end{array}$} & \multirow{2}{*}{$\begin{array}{l}\text { Differenc } \\
\text { e in } \\
\text { effective } \\
\text { ness }\end{array}$} & \multirow{2}{*}{$\begin{array}{l}\text { Percenta } \\
\text { ge of } \\
\text { improve } \\
\text { ment } \%\end{array}$} \\
\hline & & & & Freq & Effec & Freq & Effec & & \\
\hline \multirow{12}{*}{ 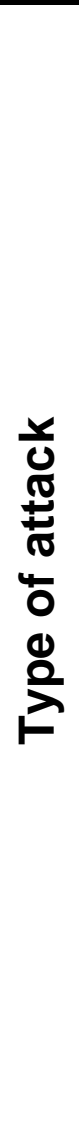 } & \multirow{2}{*}{\multicolumn{2}{|c|}{ Direct }} & $\begin{array}{c}\text { Simpl } \\
e\end{array}$ & 14 & 11 & 19 & 20 & 9 & 81.818 \\
\hline & & & Mixed & 11 & 9 & 18 & 13 & 4 & 44.444 \\
\hline & \multirow{10}{*}{ 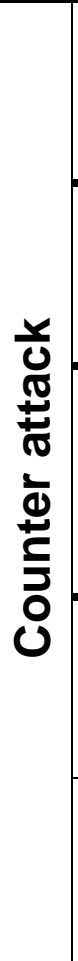 } & \multirow{2}{*}{$\begin{array}{l}\text { Sen } \\
\text { no } \\
\text { sen }\end{array}$} & $\begin{array}{c}\text { Simpl } \\
\text { Sim }\end{array}$ & 13 & 9 & 9 & 8 & -1 & -11.111 \\
\hline & & & Mixed & 3 & 1 & 2 & 1 & 0 & 0.000 \\
\hline & & \multirow{2}{*}{$\begin{array}{l}\text { Tai } \\
\text { no } \\
\text { sen }\end{array}$} & $\underset{e}{\operatorname{Simpl}}$ & 7 & 5 & 6 & 5 & 0 & 0.000 \\
\hline & & & Mixed & 6 & 1 & 9 & 4 & 3 & 300.000 \\
\hline & & \multirow{2}{*}{$\begin{array}{c}\text { Ta } \\
\text { tai } \\
\text { no } \\
\text { sen }\end{array}$} & $\underset{e}{\operatorname{Simpl}}$ & 3 & 2 & 3 & 2 & 0 & 0.000 \\
\hline & & & Mixed & 6 & 3 & 3 & 2 & -1 & -33.333 \\
\hline & & \multirow[t]{2}{*}{$\begin{array}{l}\text { Gon } \\
\text { usen }\end{array}$} & $\underset{e}{\text { Simpl }}$ & 4 & 3 & 4 & 8 & 5 & 166.667 \\
\hline & & & Mixed & 8 & 2 & 9 & 5 & 3 & 150.000 \\
\hline & & \multirow[t]{2}{*}{$\begin{array}{l}\text { Gon } \\
\text { usen }\end{array}$} & $\underset{e}{\text { Simpl }}$ & 2 & 1 & 5 & 4 & 3 & 300.000 \\
\hline & & & Mixed & 6 & 1 & 2 & 1 & 0 & 0.000 \\
\hline
\end{tabular}




\begin{tabular}{|c|c|c|c|c|c|c|c|c|c|c|}
\hline \multirow{9}{*}{ 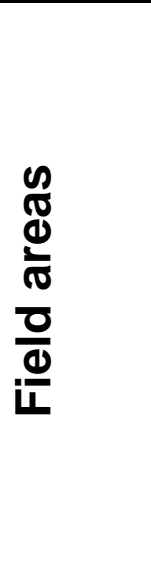 } & \multirow{3}{*}{$\mathbf{A}$} & \multirow{3}{*}{ B } & \multirow{3}{*}{ C } & $\mathbf{A}$ & 7 & 4 & 8 & 9 & 5 & 125.000 \\
\hline & & & & B & 9 & 5 & 10 & 6 & 1 & 20.000 \\
\hline & & & & C & 7 & 4 & 9 & 10 & 6 & 150.000 \\
\hline & \multirow{3}{*}{ D } & \multirow{3}{*}{$\mathbf{E}$} & \multirow{3}{*}{$\mathbf{F}$} & D & 11 & 6 & 11 & 8 & 2 & 33.333 \\
\hline & & & & $E$ & 18 & 11 & 12 & 10 & -1 & -9.091 \\
\hline & & & & $\mathbf{F}$ & 9 & 5 & 9 & 9 & 4 & 80.000 \\
\hline & \multirow{3}{*}{$\mathbf{G}$} & \multirow{3}{*}{ H } & \multirow{3}{*}{ I } & G & 7 & 4 & 10 & 8 & 4 & 100.000 \\
\hline & & & & H & 7 & 4 & 11 & 6 & 2 & 50.000 \\
\hline & & & & I & 8 & 5 & 9 & 7 & 2 & 40.000 \\
\hline \multirow{3}{*}{$\begin{array}{c}\text { Gam } \\
\text { e } \\
\text { time }\end{array}$} & \multicolumn{4}{|c|}{ First Tuesday } & 25 & 13 & 30 & 28 & 15 & 115.385 \\
\hline & \multicolumn{4}{|c|}{$\begin{array}{l}\text { Second } \\
\text { Tuesday }\end{array}$} & 31 & 15 & 28 & 23 & 8 & 53.333 \\
\hline & \multicolumn{4}{|c|}{ Third Tuesday } & 27 & 20 & 31 & 22 & 2 & 10.000 \\
\hline \multirow{4}{*}{$\begin{array}{l}\text { Gam } \\
\text { e } \\
\text { result } \\
\text { s }\end{array}$} & \multicolumn{4}{|c|}{ Failed } & 46 & 0 & 36 & 0 & 0 & 0.000 \\
\hline & \multicolumn{4}{|c|}{ One point } & 30 & 30 & 41 & 41 & 11 & 36.667 \\
\hline & \multicolumn{4}{|c|}{ Two points } & 3 & 6 & 4 & 8 & 2 & 33.333 \\
\hline & \multicolumn{4}{|c|}{ Three points } & 4 & 12 & 8 & 24 & 12 & 100.000 \\
\hline
\end{tabular}

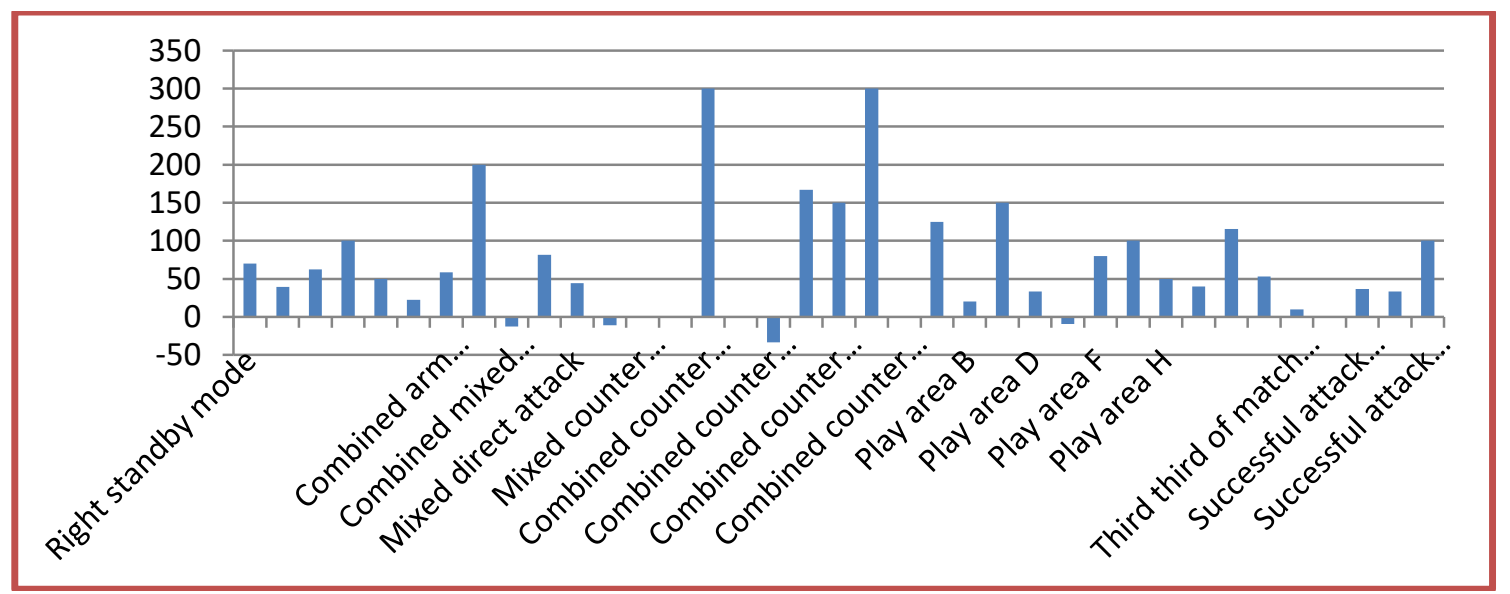

Figure (9) Percentage of improvement of the effectiveness of match results for the determinants of tactical performance of

post measurement without use and with use of biorhythm indicators in the raining program under research

Tables $(7,8)$, figures $(8,9)$ show that there are differences and improvement of the effective values of determinants of tactical attack performance of the player the sample of the research between the 
post measurement and pre measurement of the training program without use of biorhythm indicators, and between the post measurement of the training program with and without use of monthly biorhythm indicators of the player the sample of the research. The lowest and highest value of differences ranged between (1:11) and (1:15), and the lowest and highest percentage of improvement was $(15,385,300 \%)$ and $(10,300 \%)$ for the favor of post measurement (with and without) use of biorhythm indicators respectively.

There are differences and improvement of the effectiveness of the values of attack readiness position as a determinant of tactical attack performance of the player the sample of the research between the post measurement and pre measurement of the training program without use of biorhythm indicators, and between the post measurement of the training program with and without use of monthly biorhythm indicators of the player the sample of the research. The lowest and highest value of differences ranged between $(11,5)$ and $(11: 14)$, and the percentage of improvement was $(122.222,21.739 \%)$ and $(70.000,39.286 \%)$ for the favor of post measurement (with and without) use of biorhythm indicators respectively.

There are differences and improvement of the effectiveness of the values of simple (individual) attack styles by (right, left) arms, and (left, right) legs, and the mixed attack styles (arms, legs, mixed) as determinant of the tactical attack performance of the player the sample of the research between the pre measurement and post measurement of the training program without use of biorhythm indicators, and between the post measurement of the training program without use and with use of monthly biorhythm indicators of the player the sample of the research. The value of differences ranged between $(0,1,2,6,4,0,3),(7,2,2,4,5,6,-1)$. The percentage of improvement was $(0.000,33.33,100,200,50.000,0.00$, $60.000 \%)$, (62.500, 100.00, 50.000, 22.22, 58, 333, 200.000, $12.500 \%$ )and $(70.000,39.286 \%)$ for the favor of post measurement (with and without) use of biorhythm indicators respectively.

There are differences and improvement of the effectiveness of the values of simple direct attack and types of counter attack (Sen no sen, tai no sen, tat ay no sen, juno sen, juju no sen) (simple, mixed) as determinant of tactical attack performance of the player 
the sample of the research between the post measurement and pre measurement of the training program without use of monthly biorhythm indicators of the player the sample of the research. The value of differences ranged between ( 1 ن 2 ، 1- ، 1 ، 0 ، 3 ، 0 0 ، 3 ، 8

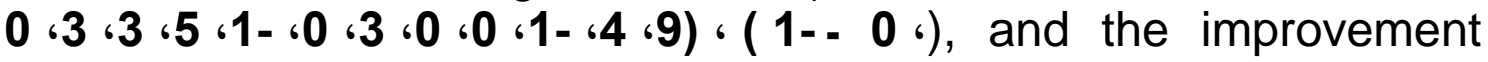
rate was (100.00، 0.000 ، 150.000 ، 0.000 ، $0.000 ، 50.000$ ، 266.667 ، 0.000 ، 11.111-) ) ( 50.000 ، 0.000 ، 100.000 ، 200.000 , 25.000 ، ، 300.000 ، 150.000 ، 166.667 ، 33.333- ، 0.000 ، 300.000 ، 0.000 $\% \mathbf{0 . 0 0 0}$ ) for the favor of post measurement (without use, with use) of the biorhythm indicators respectively.

There are differences and improvement of the effectiveness of the nine areas of field $(A, B, C, D, E, F, G, H, I, J)$ as determinant of tactical attach performance of the player the sample of the research between the pre measurement and post measurement of the training program without use of biorhythm indicator and between the post measurement of the training program without use and with use of the monthly biorhythm performance of the player the sample of the research. The value of differences ranged between ( ، $3-33$ ، 3،3 ، 2 3 ، 3 , 2، 2), (، 2 ، 4 4 4 - 2 ، 6 ، 6 ،5), and the percentage of improvement was ( 21.429 - ، $100.000 ، 300.000$ ، 150.000 ، 100.000) $\% 150.000$ ، 33.333 ، 100.000،66.667), ( ، 150.000 ، 20.000 ، 125.000 $\% 40.000$ ، 50.000 ، 100.000 ، 80.000 ، 9.091 ، 33.333) for the favor of post measurement (without, with use) of biorhythm indicators respectively.

There are differences and effectiveness of the values of parts of the game as the three (first, second and third) as determinants of tactical attack performance of the player the sample of the research between the pre measurement and post measurement of the training program without use of biorhythm indicators, and between the post measurement of the training program without using the monthly biorhythm indicators of the player the sample of the research. The value of differences ranged between $(5,2,9)$ and $(2$, $8,15)$, and the percentage of improvement was $(62.500,15.385$, $81.818 \%)$ and $(151.385,53.333,10.000 \%)$ for the favor of post measurement (with, without) use of biorhythm indicators respectively.

There are differences and improvement in the effectiveness of the calculated values of games (one point, two points, three points) as 
determinants of tactical attack performance of the player the sample of the research between the pre measurement and post measurement of the training program without use of biorhythm indicators, and between the post measurement of the training program without using the monthly biorhythm indicators of the player the sample of the research. The value of differences ranged between $(6,4,6)$ and $(11,2,12)$, and the percentage of improvement was (100.000 ، 200.000 ، 25.000\%) and ( ، 33.333 ، 36.667 $100.000 \%$ ) for the favor of post measurement (with, without) use of biorhythm indicators respectively.

Improvement of post measurement in the first phase of the program after implementation without use of biorhythm indicators is attributed to the effect of the structural content of the proposed training program that was done through the similar exercises that conform with the performance of skill styles as the muscular work, speed of performance and track of force made as well as direction and application of rated training loads individually in accordance with the use of biorhythm curves through the direction of their formation, and the use of periodic training method that was applied through the training unit, in addition to the implementation of leg movement exercises and mixing them with the various skill styles of the player using different types of attack and training in them in single and dual forms similar to what happens in the games, and training in them as training stations using the direct attack approach, and other training stations using the counter attack (su, nu, sen, tai no sen, ta tai no sen, gu nu sen, gugusen). In addition, the training loads are rated in accordance with the characteristics of training loads dynamisms as speed and force are in conformity in accordance with the direction of muscular work, in addition to the use of the games specified with duties and the various attack styles and situations used in playing times during the respective part "game training" that contained competitive exercises in the form of rated tactical duties of performance with maintenance of the principle of individual differences of players, which was reflected on the level of enforcement of tactical activity and increasing effectiveness of successful attack and overall attack during the game.

Improvement in the second measurement of the second phase of application of training program using biorhythm is due to the components of training program itself and their rating using biorhythm curves to direct training loads of tactical performance determinants in the players of the actual duel competition (kumite) in 
karate, which increases the product of the tactical sides of players and the skill styles that can be used in the suitable movements according to the distance between competitor and area to be moved in to make the suitable type of attack to the competition situation between the competitor and him, which increased the effectiveness of attack and economy of effort. This is in agreement with the notes of Ahmed Mohamed Ibrahim (2005, 2011, 2013), Haddad, M et al (2011), Heba Mohamed Ali (2012), Ahmed Mahmoud Ibrahim and EmanRashad (2014), AlaaHamdyAzmy (2014), WalaaHamdyFarghaly (2014), (2,3,4), (29), (18), (6), (9), (20).

\section{Conclusions:}

The content of proposed training program using the determinants of monthly biorhythm track for direction of training loads of special motor skills in the tactical performance showed positive effect on the values of improvement of special motor skills of the player the sample of the research from the proposed training program without use of the determinants of monthly biorhythm track. The percentages of improvement were as follows:

- Improvement of motor response speed to the counter box, gyakusuki (right) and the semi-circular short counter kickKezamiMawashi Geri (left) with percentage of (15.342, 14.090\%) respectively.

- Improvement of transitional speed forward (left) and back retreat (right) with percentage of $(12.897,18.697 \%)$ respectively.

- Improvement of the values of original and secondary directions test of the speed and agility of leg movement (right, free, left) with percentage of $(4.281,3.824,7.097)$ respectively.

- Improvement of motor speed in the pendulum step (left, right) with percentage of (15.385) respectively.

- Improvement of speed force in experimental time of (10 sec.) of the counter box- Gyakusuki (right) and semi-circular short counter kick- kezamimawashigeri (left) with percentage of (11.538, 15.385\%), respectively.

- Improvement of speed endurance in experimental time of (20 sec.) for the counter box, gyakuzuki (right) semi-circular short counter kick test, kezamimawashigeri test (left) with percentage of $(10.526,10.256 \%)$ respectively.

In addition, the content of proposed training program using the determinants of monthly biorhythmic track to direct the training loads of tactical performance have positive effect on the values of improvement of the tactical performance determinants of the player 
the sample of the research for the proposed training program without use of the determinant of monthly biorhythm track as improvement of values of effectiveness was as follows:

- Attack standby position (left, right) as determinant of attack tactical performance with improvement percentage of $(70.000$, $39.286 \%)$ respectively.

- Simple attack styles (single) with (left, right) arms and (left, right) legs, and the mixed attack styles (arms, legs, mixed) as determinant of tactical performance with percentage of (62.500, $100.00,50.000,22.22,58.333,200.000,-12.500 \%$ ) respectively.

- Types of simple direct attack and mixed attack and types of counter attack (sen nu sen, tai nu sen, ta tai nu sen, gu nu sen, gugu nu sen) (simple, mixed) as determinant of tactical and attack performance with improvement percentage of $(300.000$, $150.000,166.667,-33.333,0.000,300.000,0.000,0.000$, $11.111-0.000 \%)$ respectively.

- The nine areas of the field (A, B, C, D, E, F, G, H, I) as determinant of the tactical attack performance with improvement percentage of $(125.000,20.000,150.000,33.333,9.091,80.000$, $100.000,50.000,40.000)$ respectively.

- Points calculated in games (point, two points, three points) as determinant of the tactical attack performance with improvement percentage of $(36.667,33.333,100.000 \%)$ respectively.

\section{Recommendations:}

- To use the content of building structure that forms the proposed training program as reference by using the biorhythm indicators to direct training loads of the tactical performance in the players of the actual competition "Kumite" in karate.

- To pay attention to the research plan directed to improve the motor capacities of kumite players in karate through the other age groups.

- To pay attention to the research plans dedicated to the development of determinants of tactical performance of kumite players in karate during the other age groups to complete scientific building of karate.

- To pay attention to the research plans dedicated to the development of motor capacities of kata players in karate.

- To pay attention to the research plans dedicated to the development of technical and skill sides of kata players in karate.

\section{References}


1 Ibrahim Ali El Ebiary

2 Ahmed Ibrahim

3
Ahmed Mahmoud Ibrahim

4
Ahmed Mahmoud Ibrahim

\section{Ahmed Mahmoud Ibrahim, AmrAlla Al Bassaty}

\section{Ahmed Mahmoud Ibrahim, EmanRashad Khalil}

7 Ahmed Ibrahim, Magda Ahmed Hamouda

\section{Ahmed Mahmoud Ibrahim, Mahmoud}

Design of tactical system to penetrate the opponent's field, and its effect on the effectiveness of performance in karate players, PhD thesis, Faculty of Physical Education, Menoufiya, 2007

Encyclopedia of the determinants of theoretical sports training and application of the plans of training programs in karate, Al Maaref Establishment, Alexandria, 2005

Encyclopedia of modern trends and determinations of the methods of rating and planning the training programs of karate, $\mathrm{Al}$ Maaref Establishment, Alexandria, 2011.

Relative contribution of some determinants of tactical activity as a direction for increasing the effectiveness of attack activity of the actual fighting competition players (kumite) in karate, volume of Theories and Applications Magazine, Faculty of Physical Education for Men, Alexandria University, 2013.

Effect of directing training loads in accordance with the pattern of biorhythm on some functional significance and level of skill performance of the motor package of karate player, volume of theories and applications, faculty of physical education for men, Vol. 2 and Vol. 3, Alexandria University, 1999.

Effect of using the tactical activity on the effect of some determinants of the attack activity of some "Crugy players" in Tai Kundo, volume of the Faculty of Physical Education for Men, Alexandria University, 2014.

Effect of training loads directed to the properties of biorhythm pattern on the values of some indicators of respiratory system efficiency, volume of the magazine of theories and applications, Faculty of Physical Education for Men, Abu Qir, Alexandria, 1999AD.

Effect of the use of combination of skill performance exercises and special leg 
Ragaey Mohamed, Hossam El Din

Abdelrazek, Rabie Suleiman Mohamed

9 AlaaHamdyAzmy

$10 \begin{aligned} & \text { Sherif Mohamed } \\ & \text { Awady } \\ & \text { Ali Fahmy Al Bek }\end{aligned}$
11 ahm

Al Rules of attack, no author, 2004.

12 Ali Fahmy Al Bek, Mohamed Sabry Omar

13 EmadAbdelfattah Al Sersy

14 Omar Labib

15 Mohamed Abdelrahman Ali

16 Mohamed Abdelrahman Ali University, 2014. men, Alexandria University, 2014 Establishment, Alexandria, 1994. Education, Tanta, 2001 AD. Menoufiya, 2002 AD. movement on some determinants of the tactical activity "preparation- execution" in the players of actual fight game "kumite", Magazine of the Faculty of Physical Education for Women, Arabic version, Faculty of Physical Education in Al Gezira, Helwan

Effect of the use of attack motor packages on the development of some determinants of attack in the U-12 junior in the actual fighting competition (kumite) in karate, unpublished master thesis, faculty of physical education for

Biorhythm and sports achievement, published research, scientific conference, symposium on physical education in the solution of contemporary problems, faculty of physical education for men, Zagazig University, 1990.

Biorhythm and sports achievement, Al Maaref

Effect of training program on the development of physical and skill characteristics of karate players, PhD thesis, Faculty of Physical

Mohamed Effect of rhythm on some physical, skill and physiological variables of karate players, PhD thesis, Faculty of Physical Education,

Effect of agility of leg movements on the improvement of effective performance of some attack skills in the karate juniors, unpublished master thesis, Faculty of Physical Education, Alexandria, 2009.

Effect of the use of some tactical maps during the time and place divisions on the indicators of quantitative effectiveness of tactical performance of the kumite player in karate, $\mathrm{PhD}$ thesis, Faculty of Physical Education, 
17 Alexandria University, 2013 AD. Esaad

18 Heba Mohamed Ali Effect of parallel training on the some of some Hassan motor capacities on the level of some times of attack approaches and effectiveness of the attack behavior in the karate player, unpublished master thesis, Faculty of Physical Education for Men, Alexandria University, 2012

19 Wael Hassan Abu El Effect of the use of combination of free attack KHIR package and leg movement on the quantitative level of some attack determinants of kumite players in karate. Unpublished master thesis, Faculty of Physical Education for Men, Alexandria University, 2014.

20 WalaaHamdyFarghaly Effect of the use of tactical activity on the quantitative effectiveness of some determinants of attack activity of the players of kumite in karate, unpublished $\mathrm{PhD}$ thesis, Faculty of Physical Education for Women in Al Gezira, Helwan University, 2014.

21 Yasmine Hassan Ali Relation between biorhythm and the level of sports achievement of rhythm female players with international level, published research, scientific conference, Faculty of Physical Education for Women, Cairo, Helwan University, 1998 AD.

-22 Youssef Dahab Ali General physiology and sports physiology, Taher Bros Press, Menoufiya, 2000 AD.

23 Youssef Dahab Ali Biorhythm of fit body as indicator of academic achievement and sports activity, published research, Magazine of the Scientific Conference of gymnasium, physical fitness and exercises for all, "Qualification, Graduation", Faculty of Physical Education for Men, Alexandria University, 1993 
24 Youssef Dahab Ali

25 Youssef Dahab Ali, Youssef Dahab Ali, Mohamed

GaberBriqa, Ahmed Mahmoud Ibrahim
Physiological reserve and rating of functional efficiency, international conference on the strategies of selection and preparation of sports talents in light of technology development and information revolution in the period from 30 October to 1 November, Faculty of Physical Education for Men, Alexandria University, 2002.

Localization and rating of Ostbreg Scale for determination of the pattern of biorhythm, scientific magazine of physical and sports education, researches of the conference on future vision of physical and sports education in the Arab World, Faculty of Physical Education for Men, Haram, Helwan University, 1993.

\section{References:}

2-6 Beneke R, Beyer :Energetics of karate kumite. Eur J Appl Physiol. T, Jachner C, et al 2004.

27- Glaister M. : physiological responses, mechanisms of fatigue and Multiple sprint the influence of aerobic fitness. Sports Med. 2005. work

28- lide K, Imamura : Physiological responses of simulated karate sparring $\mathrm{H}$, Yoshimura $\mathrm{Y}$, matches in young men and boys. J Strength Cond Res et al 2008.

29- Haddad $M$, :The construct validity of session RPE during an Chaouachi A, intensive camp in young male Taekwondo athletes. Castagna C, et al Int J Sports Physiol Perform. 2011.

30- Haddad $M$, :The convergent validity between two objective Chaouachi A, methods for quantifying training load in young Castagna C, et al taekwondo athletes. J Strength Cond Res. 2012.

31- Hill. D. Smith. D Effect of time of day on the relationship between mood state, anaerobic power and capacity , perceptual and motor skills $72,82,87,1991$. 


\section{Summary of the research:}

Development of the Determinants of tactical performance with significance of the monthly Biorhythm and their effect on the results

of Kumite games in Karate

The research aims at identifying the development of determinants of tactical performance with the significance of monthly biorhythm indicators and their effect on the results of Karate. The researcher used the experimental methodology with the pre-post measurement of one player of the Egyptian national team for kumite of men. The key results were as follows:

- Improvement of motor response speed of the counter boxGyakuSuki (right) and semi-circular short counter kick kezamimawashigeri (left) with percentage of (15.342, 14.090\%), respectively.

- Improvement of transitional speed forward (left) and back retreat (right) with percentage of $(12.897,18.697 \%)$ respectively.

- Improvement of the values in the test of original and secondary direction concerning speed and agility of leg movement (right, free, left) with percentage of $(7.097,3.824,4.281)$ respectively.

- Improvement of Motor speed in the Pendulum step (left, right) with percentage of (15.385) respectively.

- Improvement of speed force in experimental time of (10 Sec.) for the counter box, gyakusuki (right) and the semi-circular short counter kick- kezamimawashigeri (left) with percentage of $(11.538,15.385 \%)$, respectively.

- Improvement of speed endurance in experimental time of (20 Sec) for the counter box- gyakusuki (right) and Semi-circular short counter kick- KezamiMawshi Geri (left) with percentage of (13.333, 13.043\%) respectively.

In addition, the content of the proposed training program using the monthly biorhythm track to direct the training loads of tactical performance showed positive effect on the values of improvement of the determinants of tactical performance of the player the sample of the research from the proposed training program without use of the determinant of monthly biorhythm as the values of improvement were as follows:

- Position of standby for attack (Left, Right) as determinant of tactical attack performancewith improvement percentage of (70.000, 39.286\%) respectively.

- Simple (single) attack styles with arms (left, right) and legs (left, right) and the mixed attack styles (arms, legs, mixed) as 
determinants of tactical attack performance with improvement percentage of ( 200.000، 58.333\% 22.22، 50.000، 100.00، 62.500 12.500-6).

- Types of simple and composite direct attack and types of counter attack (sen nu sen, tai nu sen, ta tai nu sen, gu nu sen, gugu nu sen) (simple, mixed) as determinant of tactical performance with improvement percentages of ( $300.000 \% 0.000$ ، 0.000 ، 11.111- ) 0.000 300.000، 150.000، 166.667 ، 33.333-6 0.000،) respectively.

- Nine areas of field (A, B, C, D, E, F, G, H, I) as determinant of tactical attack performance with improvement percentages of ( ) ، 100.000 ، 80.000، 9.091-\% 33.333، 150.000، 20.000، 125.000 40.000، 50،000) respectively.

- Parts of game time as the three parts (first, second and third) are determinants of tactical attack performance with improvement percentage of $(151.385,53.333,10.000 \%)$ respectively.

- Points calculated in games (one, two three) points as determinants of tactical attack performance with improvement percentage of $(36.667,33.333,100.000 \%)$ respectively. 